\title{
A Format to design Narrative Multimedia Applications for Cultural Heritage Communication
}

\author{
Elisa Rubegni \\ Università della Svizzera \\ italiana \\ via Buffi 13, 6900 Lugano \\ elisa.rubegni@usi.ch
}

\author{
Nicoletta Di Blas \\ Politecnico di Milano \\ Via Ponzio 34/5, 20133 \\ Milano \\ nicoletta.diblas@polimi.it
}

\author{
Paolo Paolini \\ Politecnico di Milano \\ Via Ponzio 34/5, 20133 \\ Milano \\ paolo.paolini@polimi.it
}

\author{
Amalia Sabiescu \\ Università della Svizzera \\ italiana \\ via Buffi 13, 6900 Lugano \\ sabiescua@usi.ch
}

\begin{abstract}
In this paper we introduce the "Instant MultiMedia" (IMM) approach to ICT-based communication. IMM is characterized for being quick (30 days to deliver the application) and low cost (5,000 US dollars for a medium-sized applications). It is therefore a suitable solution in a number of occasions: when a sudden communication need arises, in the case of small institutions with scarce resources, when niche target and content are to be addressed etc. We will introduce a concrete case-study, "Enigma Helvetia tales", a multimedia (text, images, audios) and multichannel (web, CD-rom, podcast) application that was developed in spring 2008 in the occasion of an art exhibition held in Lugano $(\mathrm{CH})$. An extensive user study - involving more than 200 users - proved the efficacy of the approach in terms of satisfaction, better understanding of content, knowledge retention and enhanced curiosity towards the event.
\end{abstract}

\section{Categories and Subject Descriptors}

D.2 [Software Engineering]: D.2.2 Design Tools and Techniques, User interfaces, D.2.10 Design, Methodologies,

H.5 [Information Interfaces And Presentation]: H.5.1 Multimedia Information Systems, H.5.4 Hypertext/Hypermedia,

J. [Computer Applications]: J.5 Arts and Humanities

\section{General Terms}

Design, Human Factors.

\section{Keywords}

Cultural heritage, User Experience, Multimedia, Multichannel, Interaction design.

\section{INTRODUCTION}

In the last years cultural institutions have explored the opportunity of using information communication technology to enhance the visitors' experience, taking into account the need of

Permission to make digital or hard copies of all or part of this work for personal or classroom use is granted without fee provided that copies are not made or distributed for profit or commercial advantage and that copies bear this notice and the full citation on the first page. To copy otherwise, or republish, to post on servers or to redistribute to lists, requires prior specific permission and/or a fee.

SAC'10, March 22-26, 2010, Sierre, Switzerland.

Copyright 2010 ACM 978-1-60558-638-0/10/03...\$10.00. information prior, during and after the visiting experience (e.g. web site, mobile guide, social media). Many types of technology platforms (mobile, wearable, tangible, web, kiosk etc.) have been used for the design of applications for communicating contents, either to support understanding or to engage visitors in the exploration of the museum exhibition. Most of the biggest art and cultural institutions experimented with the use of ICT for their purposes implementing interactive guides, social network areas, informative kiosks etc. Many attempts, both from research and the industry, have been done in these directions [e.g. 2, 3, 4]. While the possibility to offer these types of interactive experiences might be very appealing to many cultural institutions, the design and development of multimedia applications is often expensive and time consuming. Indeed, there is a correspondence between the complexity and variety of types of applications that can be created by a cultural institution and the complexity of the authoring process which stays behind it. In this paper, we introduce a new approach to ICT-based communication for cultural heritage (but no only) that may solve this impasse.

\section{The Instant Multimedia Approach}

Our approach is called Instant MultiMedia (IMM), in that it is meant to allow a fast production of multimedia applications by non-techy authors. In contrast with typical cultural heritage productions which are characterized for being time-consuming and quite expensive, IMM “speeds things up" by means of a (1) very simple and pre-defined information architecture, (2) a precise workflow and (3) a dedicated authoring tool (called "1001stories"). The information architecture is a two-level tree composed by a set of topics each with its own sub-set of details. The author can only choose how many topics/details she wants but cannot change the design schema. The workflow is a sequence of 10 steps (described in details elsewhere [5]). The most innovative one regards the way content is gathered: by means of an interview to an expert. A two-hour interview may serve as basis for a medium sized application and the process - if compared to the traditional methodology of asking the expert to produce a document - is much faster. In addition, the result is more engaging since the expert spontaneously adopts a conversational and pleasant style, much more accessible for the wide public. To create IMM applications, we use a dedicated tool called 1001stories. 1001stories delivers the multimedia narratives on several channels: web, CD-rom, podcast. Its data-entry interface is very simple (average learning time: 20 minutes) and there is practically no technological pre-requisites for using it. All these characteristics allow non technology-savvy authors to 
produce in a quick and cost-effective way multimedia narratives. But the reader may rightly ask: is the result good? Do these narratives "work" in terms of communication? In the next paragraph we will try to answer this question by means of a case study: Enigma Helvetia Tales, a multimedia multi-channel application that was created in spring 2008 in the occasion of an art exhibition held in Lugano.

\section{Enigma Helvetia Tales}

Enigma Helvetia Tales (www.enigmahelvetia.usi.ch, Fig. 1) is one of the applications developed using the IMM approach. The narrative was developed in Spring 2008 for the Cantonale Art Museum and the Museum of Art of Lugano to promote the exhibition Enigma Helvetia. Enigma Helvetia Tales was developed in one month and distributed during the exhibition for communicating the event in spring 2008.

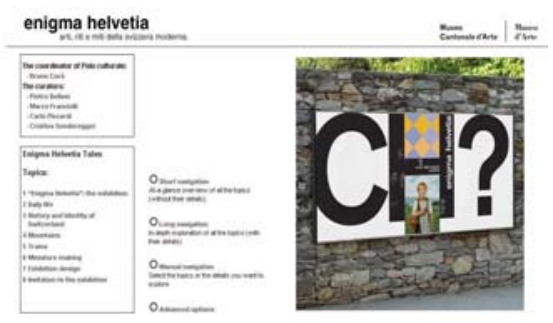

Figure 1 Enigma Helvetia tales.

The exhibition introduced the contradictions between the Swiss stereotypes about the everyday life and Swiss artistic creations. The main purpose of producing it was for supporting the visitor's experience before, during and after the visit. Enigma Helvetia Tales was the perfect case study to refine our research interests on assessing the impact of interactive communication artifacts for communicating cultural heritage.

We have focused our research around the suitability of the format for enhancing the understanding of cultural contents. In particular, in this study we aimed to answer the question: how effective is an application built on a rigid design format for communicating cultural contents?

To answer this question we have conducted a survey for measuring to what extent cultural contents can be effectively delivered in the format put forward in the IM approach. The survey was carried on from June 17th to August 17th, 2008 (when the exhibition closed). We gathered 201 questionnaires: 119 on-line and 82 on-site (at the museums).

The outcomes of the survey revealed interesting tendencies and implications. The sample of the user target shows high appreciation of the application.

Regarding the suitability of the narrative to introduce the exhibition themes $72 \%$ declared it to be very adequate (score 4 or 5 on a 1-5 scale). Data revealed a difference between people that had already visited the exhibition (53\% of the overall group) and non visitors, i.e. users who had not visited the exhibition and had the narrative as the only way to access the exhibition's themes ( $47 \%$ of the overall group). In fact, a stunning $97.5 \%$ of nonvisitors found the narrative adequate (scores from 3 to 5).
To summarize, the survey's results seem to confirm the power of the narrative both into attracting people to the exhibition and into conveying its cultural message.

\section{Conclusion}

The Instant Multimedia approach has been used for many applications and in all authoring usage cases it revealed its simplicity (especially in being used by non-techy professionals) and flexibility of use (its use has been leveraged to different domains e.g. from cultural heritage, to education, corporate communication). In the case presented, Enigma Helvetia Tales, the results yielded by this approach were evaluated from the perspective of the user experience. As demonstrated by the results of the survey, people who explored the narrative have a better understanding of the exhibition themes and for those who did not see the exhibition, it acted as spur for visiting it. Other implications and future research directions can be drawn from the study, regarding the role that this technology can play in enhancing the understanding of cultural contents before, during and after the visit to an exhibition (as for example the context of contents consumption, both physical and social). For this purpose we aim at creating a new multimedia narrative for the next exhibition to be held at Cantonale Art Museums in fall 2009 in order to deepen our understanding of its impact on the visiting experience

\section{ACKNOWLEDGMENTS}

Our thanks to people that support this research at the TEC-Lab and at the Cantonale Art Museum and the Museum of Art of Lugano.

\section{REFERENCES}

[1] Donovan, K. (1997). The Best of Intentions: Public Access, the Web \& the Evolution of Museum Information. Museums and the Web 97 Proceedings. Archives and Museum Informatics, 1997.

[2] Marti, P., Rizzo, A., Petroni, L. ,Tozzi, G., Diligenti, M. (1999). Adapting the museum: a non-intrusive user modeling approach. In Kay, J. (ed.) UM99, User Modeling, Proceedings of the Seventh International Conference. New York: Springer, pp. 311-31

[3] Proctor, N. (2005), "Off Base or On Target? Pros and Cons of Wireless and Location-Aware Applications in the Museum" Proceedings of the Tate Handheld Conference Sept 5, 2008

[4] Samis, P. (2007) Gaining Traction in the Vaseline: Visitor Response to a Multi-Track Interpretation Design for Matthew Barney: DRAWING RESTRAINT . In J. Trant and D. Bearman (eds). Museums and the Web 2007: Proceedings. Toronto: Archives \& Museum Informatics, published March 31, 2007

[5] Di Blas, N., Bolchini, D., Paolini, P.: Instant Multimedia: A New Challenge for Cultural Heritage. In: Bearman, D. \& Trant, J. (eds.) Museums and the Web 2007. Published at http://www.archimuse.com/mw2007/papers/diBlas/diBlas.ht ml. Accessed 7 July 2007 